\title{
STUDI TENTANG MOTIVASI KERJA TENAGA NON PNS DI PUSKESMAS PERAWATAN CEMPAE KOTA PAREPARE
}

\author{
Study On The Motivation Of Non Civil Servant Employment In Puskesmas Perawatan \\ Cempae Kota Parepare
}

\author{
Hardianti Merdekawati B, Usman, Makhrajani Majid \\ (Program Studi Kesehatan Masyarakat Fakultas Ilmu Kesehatan Universitas Muhammadiyah \\ Parepare) \\ (anti170707@gmail.com/082292074755)
}

\begin{abstract}
ABSTRAK
Motivasi pada dasarnya adalah kondisi mental yang mendorong dilakukannya suatu tindakan (action atau activities) dan memberikan kekuatan yang mengarah kepada pencapaian kebutuhan, memberi kepuasan ataupun mengurangi ketidakseimbangan. Tujuan penelitian adalah Untuk mengetahui dan menganalisis kebijakan pimpinan, hubungan antar manusia dan kondisi kerja terhadap motivasi kerja di Puskesmas Perawatan Cempae Kota Parepare. Penelitian menggunakan metode penelitian deskriptif dengan pendekatan survey yaitu suatu metode penelitian yang dilakukan dengan tujuan utama untuk mengetahui gambaran atau deskriptif tentang suatu keadaan secara objektif. Populasi dalam penelitian ini adalah seluruh tenaga Non PNS di Puskesmas Cempae sebanyak 53 orang. Teknik pengambilan sampel dilakukan dengan teknik total sampling yaitu semua anggota populasi dijadikan sampel yaitu sebanyak 53 tenaga Non PNS. Analisis data menggunakan analisis univariat dan deskriptif. Hasil penelitian menunjukkan ada hubungan kebijakan pemimpin yaitu cukup baik sebanyak (41,5\%), sangat baik sebanyak $(39,6 \%)$ dan baik sebanyak $(18,9 \%)$. Hubungan denga rekan kerja yaitu baik sebanyak $(58,5 \%)$, cukup baik sebanyak (24,5\%) dan sangat baik sebanyak $(17,0 \%)$. Kondisi kerja yakni cukup baik sebanyak $(52,8 \%)$, baik sebanyak $(45,3 \%)$ dan sangat baik sebanyak (1,9\%) terhadap motivasi kerja tenaga Non PNS di Puskesmas Cemape Kota Parepare. Kesimpulan penelitian adalah motivasi tenaga Non PNS di Puskesmas Cempae Kota Parepare tahun 2018 adalah sangat baik sebanyak 29 responden (54,7\%), cukup baik sebanyak 23 responden $(43,4 \%)$ sedangkan kurang baik sebanyak 1 perawat $(1,9 \%)$.
\end{abstract}

\section{Kata kunci: Motivasi, kebijakan, hubungan dengan rekan kerja, kondisi kerja}

\begin{abstract}
S
Motivation is basically a mental condition that encourages an action (action or activity) and provides strength that leads to achieving needs, giving satisfaction or reducing imbalances. The aim of the study was to find out and analyze the leadership policies, human relations and working conditions on work motivation in the Cempae Health Center in the Municipality of Parepare. The study uses descriptive research methods with a survey approach that is a method of research carried out with the main purpose of knowing the description or description of a situation objectively. The population in this study were 53 non-Civil Servant personnel at the Cempae Community Health Center. The sampling technique is done by total sampling technique, which is that all members of the population are sampled as many as 53 Non Civil Servant personnel. Data analysis using univariate and descriptive analysis. The results of the study showed that there was a relationship between the leaders' policies which were quite good
\end{abstract}


(41.5\%), very good (39.6\%) and good (18.9\%). The relationship with coworkers is good (58.5\%), quite good (24.5\%) and very good (17.0\%). The working conditions are quite good (52.8\%), both as much (45.3\%) and very good (1.9\%) for the motivation of working Non Civil Servant staff at the Cemape Puskesmas in Parepare City. The conclusion of the study was that the motivation of Non Civil Servant personnel in the Parepare City Cempae Health Center in 2018 was very good as many as 29 respondents (54.7\%), quite good as many as 23 respondents (43.4\%) while not as good as 1 nurse $(1.9 \%)$..

Keywords: Motivation, policies, relationships with colleagues, working conditions 


\section{PENDAHULUAN}

Sistem Kesehatan Nasional adalah suatu tatanan yang mencerminkan upaya bangsa Indonesia untuk meningkatkan kemampuannya mencapai derajat kesehatan yang optimal sebagai perwujudan kesejahteraan umum seperti yang dimaksud dalam Undang-Undang Dasar 1945. Tujuan pembangunan kesehatan adalah untuk meningkatkan kesadaran, kemauan dan kemampuan hidup sehat bagi setiap orang agar terwujud derajat kesehatan masyarakat yang optimal. Untuk mencapai tujuan pembangunan kesehatan menuju terciptanya Indonesia sehat, maka sangat dibutuhkan dukungan Sumber Daya Manusia (SDM) yang memiliki kemampuan yang selaras dengan kebutuhan dan tuntutan perkembangan terutama dalam menghadapi tantangan masa depan semakin kompleks. ${ }^{1}$

Motivasi pada dasarnya adalah kondisi mental yang mendorong dilakukannya suatu tindakan (action atau activities) dan memberikan kekuatan yang mengarah kepada pencapaian kebutuhan, memberi kepuasan ataupun mengurangi ketidakseimbangan. Hubungan dengan rekan kerja adalah keadaan dimana rekan kerja menunjukkan sikap bersahabat dan mendorong serta dapat memberikan motivasi untuk melaksanakan tugas-tugas dalam suatu oragnisasi atau instansi. Apabila hubungan dengan rekan kerja baik maka motivasi kerja juga semakin baik begitupun sebaliknya jika terdapat hubungan dengan rekan kerja kurang baik maka akan mempengaruhi kurangnya motivasi untuk mengerjakan setiap pekerjaan. Sumber daya manusia merupakan aspek penting organisasi dan motor penggerak proses manajemen. Di tangan manusialah semua sumber daya lainnya (input) diolah dan digunakan untuk menunjang tercapainya tujuan organisasi yang telah ditetapkan.

Kebijakan adalah keputusan/ pernyataan yang dikeluarkan oleh pimpinan. Setiap kebijakan yang dikeluarkan oleh pimpinan dapat memberikan pegaruh motivasi dalam melaksanakan program pokok dalam instansi tersebut. Terjadinya perubahan atau adanya ketidaksesuaian kebijakan yang dikeluarkan pimpinan dapat mengurangi motivasi pegawai dalam mengerjakan setiap tugas-tugasnya.

Selain itu kondisi kerja juga memberikan pengaruh penting dalam memberikan motivasi bagi setiap pegawai. Seperti yang diketahui bahwa serangkaian kondisi atau keadaan lingkungan kerja dari suatu perusahaan yang menjadi tempat kerja dari para karyawan yang bekerja dalam lingkungan tersebut. Adanya kondisi kerja yang baik dapat memberikan kenyamanan bagi setiap pekerja dan dapat menjadi sebuah motivasi bagi pekerja agar dapat menjalankan setiap aktivitas kerja dengan sebaik- baiknya.

\section{BAHAN DAN METODE}

Jenis penelitian yang digunakan adalah deskriptif dengan pendekatan survey. Penelitian dilaksanakan di puskesmas 
perawatan Cempae Kota Parepare pada bulan Juli hingga Agustus 2018. Adapun rumusan masalahnya yaitu adakah peranan kebijakan pimpinan terhadap motivasi kerja tenaga NON PNS, adakah peranan hubungan dengan rekan kerja terhadap motivasi kerja tenaga NON PNS, dan adakah peranan kondisi kerja terhadap motivasi kerja tenaga NON PNS di Puskesmas Perawatan Cempae Kota Parepare.

Populasi dalam penelitian ini adalah seluruh tenaga Non PNS di Puskesmas Cempae. Pengambilan sampel dilakukan dengan total sampling sebanyak 53 tenaga Non PNS.

Pengambilan data primer menggunakan kuesioner yang di bagikan pada 53 Tenaga Non PNS. Data sekunder berupa jumlah tenaga Non PNS diperoleh di Puskesmas Cempae Kota Parepare. Analisis data menggunakan analisis univariat dan deskriptif.

\section{HASIL}

Hasil penelitian menunjukkan bahwa karakteristik responden berdasarkan umur ( Tabel 1) yaitu tertinggi pada umur antara 2630 tahun sebanyak 23 responden atau $43,4 \%$, dan terendah pada umur antara 36-40 tahun sebanyak 5 responden atau 9,4\%. Berdasarkan jenis kelamin, yang paling tinggi adalah perempuan sebanyak 48 responden atau 90,6\%, dan jenis kelamin laki-laki sebanyak 5 responden atau 9,4\% Berdasarkan masa kerja, yang paling tinggi

pada masa kerja selama 0-7 tahun sebanyak 37 responden atau $69,8 \%$, dan terendah pada masa kerja 8-14 tahun sebanyak 16 responden atau $30,2 \%$.

Responden yang menyatakan kebijakan baik sebanyak 10 responden (18,9\%), cukup baik sebanyak 22 responden (41,5\%), dan sangat baik sebanyak 21 responden (39,6\%). Dengan jawaban cukup baik terbanyak pada point 3 dan 5 yakni "Kebijakan yang keluar menghargai profesi sesuai dengan profesionalisme" dan "Rekan kerja yang tercipta dan saling membangun" dengan jawaban terbanyak 24 reponden atau 45,3\%,(Tabel 2).

Tabel 3 menunjukkan bahwa responden yang menyatakan hubungan dengan rekan kerja baik sebanyak 31 responden (58,5\%), cukup baik sebanyak 13 responden $(24,5 \%)$, dan sangat baik sebanyak 9 responden $(17,0 \%)$. Dengan jawaban baik terbanyak pada point 5 yakni "Perbedaan suku, ras, agama dan antar golongan" dengan jawaban terbanyak 35 reponden atau $66,0 \%$.

Kondisi kerja responden seperti yang tertera pada Tabel 4 menunjukkan bahwa kondisi kerja yang baik sebanyak 24 responden $(45,3 \%)$, cukup baik sebanyak 28 responden (52,8\%), dan sangat baik sebanyak 1 responden (1,9\%). Dengan jawaban cukup baik terbanyak pada point 1 yakni "Nyaman dengan tempat kerja" dengan jawaban terbanyak 33 reponden atau $62,3 \%$ 
Tabel 5 menunjukkan bahwa responden yang menyatakan motivasi kurang baik sebanyak 1 responden (1,9\%), cukup baik sebanyak 23 responden $(43,4 \%)$, dan sangat baik sebanyak 29 responden $(54,7 \%)$. Dengan jawaban sangat baik terbanyak pada point 1 yakni "Pujian atas hasil kerja yang baik" dengan jawaban terbanyak 39 reponden atau $73,6 \%$.

\section{PEMBAHASAN}

Motivasi adalah kondisi (energi) yang menggerakkan dalam diri individu yang terarah untuk mencapai tujuan organisasi. Motivasi muncul dari dua dorongan, yaitu dorongan dari dalam diri sendiri (internal motivation) dan dorongan dari luar diri/pihak lain (external motivation). Tingkatan motivasi tersebut rendah, sedang dan tinggi. Perbedaan tingkatan motivasi individu dalam suatu organisasi sangat mempengaruhi hasil kerja dan bahkan kinerjanya di dalam organisasi. $^{2}$

Peranan manusia dalam mencapai tujuan tersebut sangat penting dalam pencapaian tujuan organisasi. Untuk menggerakkan manusia agar sesuai dengan yang dikehendaki organisasi, maka haruslah dipahami motivasi manusia bekerja pada suatu organisasi, karena motivasi inilah yang menentukan perilaku orang - orang untuk bekerja atau dengan kata lain perilaku merupakan cerminan yang paling sederhana dari motivasi. Dalam pengukuran motivasi itu sendiri dapat dilihat dari dua faktor yaitu faktor intrinsik dan faktor ekstrinsiknya untuk menghasilkan baik dan buruknya kinerja dalam suatu organisasi.

Pada Tabel 2 menunjukkan bahwa sebagian besar pegawai dapat menunjukkan motivasinya berdasarkan kebijakan yang dikeluarkan oleh direktur/kepala puskesmas. Hal ini dikarenakan adanya pemberian insentif dan promosi jabatan oleh pimpinan bagi pegawai yang memperlihatkan kinerja yang baik dalam upaya meningkatkan motivasi kerjanya. Hal ini dapat menunjukkan bahwa kebijakan yang dikeluarkan oleh pimpinan menyebabkan semangat dalam bekerja, sehingga para tenaga honorer merasa termotivasi dengan kebijakan yang dikeluarkan oleh kepala puskesmas. Jadi semakin tinggi kebijakan kepala puskesmas maka semakin tinggi motivasi kerja tenaga Non PNS.

Sejalan dengan teori Robbins (2003), mengatakan komitmen organisasi adalah suatu keadaan dimana seorang karyawan memihak pada kebijakan suatu organisasi yang tujuannya untuk memelihara produktifitas kerja anggota organisasi tersebut meskipun komitmen pemimpin 
ada yang menyatakan kurang baik namun kenyataannya tetap berpengaruh secara signifikan terhadap kinerja perawat. Adapun kebijakan pemimpin pada tenaga Non PNS berupa sikap pemimpin terhadap setiap kebijakan yang dikeluarkan, dan dukungan pemimpin pada setiap pekerjaan yang dilakukan. $^{3}$

Pada Tabel 3 menunjukkan bahwa hubungan dengan rekan kerja yang baik. Hal ini dikarenakan adanya penghargaan yang cukup baik sesama rekan kerja sehingga lebih termotivasi dalam melaksanakan program kerja. Sehingga dapat disimpulkan bahwa semakin tinggi hubungan dengan rekan kerja maka semakin baik pula motivasi kerja tenaga Non PNS di Puskesmas Cempae Kota parepare.

Hasil penelitian ini sejalan dengan penelitian yang dilakukan oleh Ananda Amalia Rusfa (2014) yang menyatakan motivasi pegawai berdasarkan faktor ekstrinsiknya yang sangat dominan adalah hubungan antar pribadi dengan skor rata - ratanya sebesar $4,42 .{ }^{4}$

Hasil penelitian ini sejalan dengan teori yang dikemukakan oleh Herzberg (1996), dimana ada serangkaian kondisi ekstrinsik yang mempengaruhi seseorang dalam bekerja seperti upah, jaminan pekerjaan, kondisi kerja, status, prosedur, mutu supervisi dan mutu hubungan pribadi dengan rekan kerja, atasan, atau bawahan. Bila faktor-faktor tersebut tidak terpenuhi, akan menimbulkan ketidakpuasan atau kejenuhan dalam diri seseorang sehingga mempengaruhi perilaku dalam bekerja yang pada akhirnya akan berdampak terhadap kinerja mereka. ${ }^{5}$

Tabel 4 menunjukkan bahwa sebagian besar responden menyatakan kondisi kerja baik. Hal ini dikarenakan adanya rasa nyaman pada tempat kerja karena terjalinnya komunikasi yang baik antara atasan, serta fasilitas yang tersedia cukup membantu dalam melaksanakan pekerjaan. Sehingga tenaga honorer lebih termotivasi dalam bekerja. Sehingga dapat disimpulkan bahwa semakin baik kondisi kerja maka semakin baik pula motivasi kerja tenaga Non PNS di Puskesmas Cempae Kota parepare.

Hasil penelitian ini sejalan dengan penelitian Budiman A, Darmawansyah, Amir MY (2013) yang menyatakan responden yang memiliki kondisi kerja yang baik lebih besar presentasinya $(78,3 \%)$ dalam motivasi kerja yang baik dibandingkan dengan responden yang memiliki kondisi kerja buruk (33,3\%). Dari hasil uji statistik diperoleh nilai $\mathrm{p}=0,024(\mathrm{p}<0,05)$ dengan 
demikian Ho ditolak. Hal ini berarti ada hubungan antara kondisi kerja dengan motivasi kerja pegawai puskesmas. ${ }^{6}$

Kondisi kerja atau Lingkungan kerja yang mendukung pasti akan memberikan kenyamanan dan keefektifan dalam bekerja. Sejalan dengan Penelitian yang dilakukan oleh Hasan (2012) tentang Pengaruh Lingkungan Kerja Terhadap Kinerja Aktivis Pada Lembaga Swadaya Masyarakat Di Kota Banda Aceh 64.2\%. Artinya kinerja karyawan pada Lembaga Swadaya Masyarakat di Kota Banda Aceh mempunyai hubungan yang erat dengan faktor -faktor lingkungan kerja fisik. $^{7}$

\section{KESIMPULAN DAN SARAN}

Dari hasil penelitian yang dilakukan di wilayah kerja Puskesmas Cempae Kota Parepare, didapatkan kesimpulan bahwa ada peranan kebijakan pemimpin, hubungan rekan kerja, dan kondisi kerja terhadap motivasi kerja tenaga Non PNS di Puskesmas Cempae Kota Parepare. Disarankan bagi instansi terkait memberikan motivasi yang tinggi kepada tenaga Non PNS melalui pemberian insentif untuk lebih meningkatkan lagi motivasi kerja serta memberi pengakuan terhadap hasil kerja dengan cara memberikan penghargaan dan pujian atas prestasi kerja yang dicapai. Perlunya terjalin hubungan yang harmonis dengan rekan kerja untuk saling memperhatikan sinkronisasi antara tujuan bersama dengan tujuan masing-masing individu, tetap menciptakan dan meningkatkan suasana pergaulan yang menyenangkan, hubungan antara individu yang wajar, sadar akan hakikat individu yang lain serta memberikan suatu dorongan atau motivasi. Bagi peneliti selanjutnya yang ingin menganalisis faktor-faktor yang mempengaruhi motivasi tenaga Non PNS khususnya pada wilayah kerja Puskesmas Cemape Kota Parepare disarankan meneliti variabel lain yang tidak termasuk dalam penelitian ini.

\section{DAFTAR PUSTAKA}

1. [Depkes RI] Departemen Kesehatan Republik Indonesia. Jakarta: Indonesia Sehat 2010. Menteri Kesehatan RI. 1999.

2. Mangkunegara, Prabu A. Perilaku Dan Budaya Organisasi. Bandung: Refika Aditama. 2010.

3. Robbins. Pengaruh Motivasi Kepemimpinan Dalam Kinerja Perawat. 2003. Available at : (Http:// Www.Uniska-Bjm.Ac.Id) [diakses tanggal 01 Juli 2018]

4. Rusfa AA. Motivasi Kerja Pegawai Kantor Kecamatan Panakkukang Dalam Pelayanan Administrasi 
Kepada Masyarakat. Makasaar.

Fakultas Ilmu Sosial Dan Ilmu Politik

Unhas. 2014. Available at :

(https://scholar.googgle.co.id)

[diakses tanggal 7 Agustus 2018]

5. Herzberg. Dasar-Dasar

Manajemen. Diterjemahkan Oleh

Malayu S.P Hasibuan. Edisi

Kedua. Jakarta : Bumi Aksara. 1996.

6. Budiman A, Darmawansyah, Amir MY. 2013. Analisis Faktor Yang

Berhubungan Dengan Motivasi Kerja Pegawai Di Puskesmas Labakkang Kabupaten Pangkep.
Makassar. Administrasi Dan

Kebijakan Kesehatan Masyarakat Unhas. 2013. Available at : (https://scholar.google.co.id)

[diakses tanggal 26 November 2018]

7. Hasan, Hayati S. Pengaruh Lingkungan Kerja Terhadap Kinerja Aktivis Pada Lembaga Swadaya Masyarakat Di Kota Banda Aceh. 2012. Available at : (https://scholar.google.co.id)

[Diakses pada tanggal 6 Agustus 2018] 


\section{LAMPIRAN}

Table 1. Distribusi Karakteristik Responden Menurut Umur, Jenis Kelamin dan Masa Kerja di Puskesmas Cempae Kota Parepare

\begin{tabular}{ccc}
\hline Karakteristik Responden & (f) & $(\boldsymbol{\%})$ \\
\hline Kelompok Umur (Tahun) & & \\
$20-25$ & 13 & 24,5 \\
$26-30$ & 23 & 43,4 \\
$31-35$ & 12 & 22,6 \\
$36-40$ & 5 & 9,4 \\
\hline Jenis Kelamin & & \\
Laki-Laki & 5 & 9,4 \\
Perempun & 48 & 90,6 \\
\hline Masa Kerja (Tahun) & & \\
0-7 & 37 & 69,8 \\
$8-14$ & 16 & 30,2 \\
\hline Total & $\mathbf{5 3}$ & $\mathbf{1 0 0 , 0}$ \\
\hline
\end{tabular}

Table 2. Distribusi Responden Berdasarkan Variabel "Kebijakan” Di Puskesmas Cempae Kota Parepare.

\begin{tabular}{ccc}
\hline Kebijakan & $(\mathbf{f})$ & $(\boldsymbol{\%})$ \\
\hline Sangat Baik & 21 & 39,6 \\
Baik & 10 & 39,6 \\
Cukup Baik & 22 & 41,5 \\
\hline Total & $\mathbf{5 3}$ & $\mathbf{1 0 0 , 0}$ \\
\hline
\end{tabular}

Table 3. Distribusi Responden Berdasarkan Variabel "Hubungan dengan Rekan Kerja" di Puskesmas Cempae Kota Parepare.

\begin{tabular}{ccc}
\hline Hubungan Dengan Rekan Kerja & $(\mathbf{f})$ & $(\boldsymbol{\%})$ \\
\hline Sangat Baik & 9 & 17,0 \\
Baik & 31 & 58,5 \\
Cukup Baik & 13 & 24,5 \\
\hline Total & $\mathbf{5 3}$ & $\mathbf{1 0 0 , 0}$ \\
\hline
\end{tabular}

Table 4. Distribusi Responden Berdasarkan Variabel "Kondisi Kerja" di Puskesmas Cempae Kota Parepare.

\begin{tabular}{ccc}
\hline Kondisi Kerja & $(\mathbf{f})$ & $(\boldsymbol{\%})$ \\
\hline Sangat Baik & 1 & 1,9 \\
Baik & 24 & 45,3 \\
Cukup Baik & 28 & 52,8 \\
\hline Total & $\mathbf{5 3}$ & $\mathbf{1 0 0 , 0}$ \\
\hline
\end{tabular}


Table 5. Distribusi Responden Berdasarkan Variabel “ Motivasi” di Puskesmas Cempae Kota Parepare.

\begin{tabular}{ccc}
\hline Motivasi & $(\mathbf{f})$ & $(\boldsymbol{\%})$ \\
\hline Sangat Baik & 29 & 54,7 \\
Cukup Baik & 23 & 43,4 \\
Kurang Baik & 1 & 1,9 \\
\hline Total & $\mathbf{5 3}$ & $\mathbf{1 0 0 , 0}$ \\
\hline
\end{tabular}

